\title{
VOCES E IDENTIDADES: EXPERIENCIAS DE MUJERES GUATEMALTECAS DURANTE LA GUERRA
}

\author{
Silvia Soriano Hernández
}

RESUMEN: A partir de testimonios de mujeres guatemaltecas en un escenario de guerra, se reflexiona en las identidades que surgen en mujeres violentadas que encontraron formas de significarse, a partir de unir sus voces, integrándose a alguna estructura organizativa donde aprendieron a darle un nuevo sentido a su vida. Obviando la victimización, se rescata a sujetos sociales que se fueron descubriendo como actores que en una situación adversa, demostrando una entereza que les abrió nuevas perspectivas en su cotidianidad. El análisis de su discurso, para comprender su punto de vista I rescatar sus vivencias.

PalABRAS ClaVE: Identidad, Género, Guerra, Racismo, Simbolismo, Discurso.

ABSTRACT: Based on Guatemalan women testimonies in a war scenario, this article deals with the women' identities that arise from being victims of violence, and that found a meaning by unifying their voices, and by joining organizations that help them find that meaning in their lives. Putting aside the victimization, this paper focuses on social subjects that became doers in an adverse situation, showing a strength that opened new perspectives in their daily lives. Their discourse is explored to understand their point of view.

KEYS WORDS: Identity, Gender, War, Racism, Symbolism, Discourse.

Las vivencias dentro de una guerra son por lo general desgarradoras, ya que se asocian directamente con la muerte, con las víctimas, con el dolor. Para organismos como la Cruz Roja Internacional, aquellas personas que logran sobrevivir a cualquier catástrofe -incluso un conflicto bélico - deben continuar su vida no como víctimas, sino como sobrevivientes activos. Sólo que lograrlo no es fácil.

* Centro Coordinador y Difusor de Estudios Latinoamericanos, UNAM (ssoriano@ servidor.unam.mx). 
Gran parte de estos supervivientes activos son mujeres que vivieron durante un extenso periodo de violencia. En Guatemala se firmó una paz negociada en 1996, tras 36 años de conflicto. Para la mayoría de mujeres guatemaltecas la experiencia de la guerra - con todo lo difícil que fue, con las secuelas que aún se cargan, con los costos materiales y emocionales que implica - es una vivencia pasada que permanece en su presente. Las negociaciones, los acuerdos de paz y la desmovilización de la guerrilla son signos de que la guerra - por lo menos la revolucionaria y con ella la contrainsurgente- quedó atrás. Pero la paz, como muchos han afirmado, no es sólo ausencia de guerra.

La reflexión con cierta distancia histórica en Guatemala otorga una mirada diferente. Ya no hay la esperanza de que con la revolución se podría construir un mundo nuevo por lo que el discurso se torna contradictorio. Muchas personas valoran lo que se vivió y reconocen grandes avances en la sociedad que emergió tras la firma de los acuerdos de paz, pero para algunas otras, los costos son enormes y no se equiparan con los logros. Sea como sea, ninguna es la misma y la identidad emanada de un conflicto lo confirma. El objetivo de las siguientes páginas es rescatar voces en femenino en el contexto de una guerra para descubrir identidades que nacieron de su experiencia. Se toma como base esas voces que recrean vivencias para construir un conocimiento que debe necesariamente contextualizarse en el uso de la palabra, de un discurso que se apropia quien lo va elaborando. Un discurso que ayuda a pensar cómo se establece una relación estrecha entre alguna mujer como sujeto social y sus relatos que no están exentos de emociones, sino más bien todo lo contrario. Ello nos traslada hacia la simbolización y al discurso como elementos que dan forma a la naturalización de procesos sociales. Durante una guerra se hace más evidente el uso del discurso para descalificar a quienes son los adversarios así como a quienes se considera inferiores. ${ }^{1}$

1 De alguna manera los zapatistas se adelantaron a esto al explicitar un discurso que los identifica como los excluidos históricamente, pero también como los más dignos, como aquellos que ya no están dispuestos a seguir ocupando el lugar asignado. 
El propósito central de este trabajo es presentar múltiples identidades al rescatar las voces de mujeres marginales que se alejan del recurso de la victimización. Mostrar a mujeres que frente a un escenario adverso dieron muestra de entereza y encontraron fuerzas en una instancia organizativa fuera del tipo que fuera: legal o clandestina, vinculada a la Iglesia o a un grupo guerrillero, de mujeres o mixta. Mujeres que fueron construyendo y descubriendo identidades que desconocían al encontrar posibilidades de acción en las que se reconocieron y con las cuales resignificaron su vida futura sin mirar hacia atrás.

No puedo dejar de mencionar que si bien la identidad de las mujeres tiene múltiples voces, difícilmente se desliga de una conciencia de la maternidad. Ésta, siendo asignada culturalmente, genera una fuerte subordinación. La mujer madre no es sólo la responsable de dar la vida, sino también de preservarla, otra de sus funciones asignadas sobre la base de la cual girarán muchas de sus acciones. ${ }^{2}$ En tiempos de guerra, cuidar la vida de los otros es parte de sus responsabilidades que no logra cumplir cabalmente, pero tampoco consigue romper con el mito que se simboliza al ser madre. A pesar de que la muerte forma parte del vocabulario cotidiano $-\mathrm{y}$ no me refiero sólo a la frase de "patria o muerte..."- el conflicto que surge de su identidad maternal no las abandona. A partir de voces diversas que son reflejo de varias experiencias, rastrearé algunas identidades que se fueron formando en un escenario de guerra. La mujer combatiente, la militante, la familiar de algún muerto o desaparecido, mujeres con voz e identidad múltiple.

2 Para un trabajo más profundo sobre la maternidad como construcción social, puede consultarse: GEM, Repensar y politizar la maternidad. Un reto de fin de milenio, México, Grupo Educación Popular con Mujeres, A. C., 1994 y Mitos, realidades y propuestas sobre la maternidad, México, Grupo de Educación Popular con Mujeres, A. C., 1994. Marcela Lagarde, Los cautiverios de las mujeres: madresposas, monjas, putas, presas y locas, 3a. ed., México, UnAM, 1997 (Col. Posgrado). Silvia Tubert, Mujeres sin sombra. Maternidad y tecnología, Madrid, Siglo XXI, 1991 (Desigualdades y diferencias). Y más centrada en las vivencias dentro de una guerra revolucionaria ver el interesante trabajo de Norma Vázquez, Cristina Ibáñez y Clara Murguialday, Mujeres-montaña. Vivencias de guerrilleras y colaboradores del FMLN, Madrid, Horas y horas, 1995 (Cuadernos inacabados, 22). 
Como pretendo rescatar a algunas mujeres vistas como sujetos sociales que no se quedaron en víctimas de la violencia indiscriminada, comenzaré por explicitar los postulados con los cuales se desarrolla el feminismo en un contexto latinoamericano.

\section{RE-PENSAR AL FEMINISMO}

Básicamente me interesa pensar al feminismo a partir de la perspectiva que lo considera como una corriente que lucha contra todo tipo de opresión, incluyendo la opresión sexual.

El feminismo como corpus teórico es un vector importante respecto a la crítica a la modernidad capitalista. Desde la experiencia del sujeto en femenino, de su condición de mayoría marginada y generalmente subordinada, el impulso crítico feminista tiende a desconstruir la univocidad de los universales-neutros-ilustrados: la historia, el progreso, la razón, el hombre, la familia, la cultura desujetándose para hacer hablar a contrapelo las "microhistorias" de su constitución.

De esta manera, las investigaciones feministas han desbordado lo que podríamos denominar su preocupación inicial, esto es, la injusticia de la opresión de la mujer en la sociedad sexista, y han ampliado su horizonte crítico a los fundamentos de la civilización moderna y sus dispositivos. En el centro de este desplazamiento teórico se encuentra la categoría de género, la cual implica una transformación de paradigmas al interior de las disciplinas sociales así como una definición heurística del feminismo. ${ }^{3}$

Dos elementos considero centrales en la anterior reflexión: el aporte de la experiencia del sujeto en femenino considerado como minoría (o mayoría marginada) y el paso adelante dado por el feminismo al desbordar su preocupación inicial, ampliando el análisis crítico hacia todo tipo de opresión. Retomo de Joan Scott algunos elementos que conforman lo que la autora desarrolla como categoría de género, con la salvedad - hecha por ella misma - de que es un término que ha ido evolucionando.

${ }^{3}$ Márgara Millán, Derivas de un cine femenino, México, Porrúa/UnAM-PUEG, 1999, p. 22. 
Entendemos por género una cualidad fundamentalmente social de las distinciones basadas en el sexo; un rechazo al determinismo biológico implícito en términos como "sexo" o "diferencia sexual"; un concepto que designa relaciones sociales entre los sexos y que denota "construcciones culturales". Es decir, una creación social de ideas sobre los papeles apropiados para mujeres y hombres. "El uso de género pone de relieve un sistema completo de relaciones que puede incluir el sexo o es directamente determinado por la sexualidad". ${ }^{4}$ Hablar de género implica entonces referirse a relaciones sociales y romper con un esquema que determina que ciertas características no naturales, le son propias a los hombres o a las mujeres simplemente por el sexo al que pertenecen.

Para Scott el género se definirá como "un elemento constitutivo de las relaciones sociales basadas en las diferencias que distinguen los sexos además de que el género es una forma primaria de relaciones significantes de poder". ${ }^{5} Y$ esta relación primaria de poder implica una subordinación que se justifica a través de discursos cuyo contenido ha influenciado a la sociedad. Por medio de éstos se ha reproducido la idea de que las mujeres conservan ciertas características que las diferencian de los hombres pero que además las hacen inferiores, pues sus atributos naturales no son iguales a los de aquellos, haciendo extensivos estos atributos naturales, a lo que es propiamente social. Esto es lo que se entiende de acuerdo con Scott como "forma primaria de relaciones significantes de poder", la ejercida por un sexo sobre el otro, el dominio del sexo masculino sobre el femenino. Una relación de poder.

Ahora bien, concuerdo con Buordieu que todo poder admite una dimensión simbólica, pero se añade el tema del racismo: "El sexismo es un esencialismo: al igual que el racismo, étnico o clasista, busca atribuir diferencias sociales históricamente construidas a una naturaleza

4 Joan W. Scott, "El género: una categoría útil para el análisis histórico", en Marta Lamas [comp.], El género: la construcción cultural de la diferencia sexual, México, Miguel Ángel Porrúa/PUEG, 1996, pp. 265-302.

5 Ibid., p. 289. 
biológica que funciona como una esencia de donde se deducen de modo implacable todos los actos de la existencia". ${ }^{6}$

Construcciones sociales que se han edificado históricamente dando forma al esencialismo (que puede tener varias caras). Otra idea que se expresa al hablar de género es aquella que nos remite necesariamente a tocar las relaciones de poder y en ese sentido también a señalar que alguien lo detenta en perjuicio de otro, esta forma primaria antecede, por tanto, a muchas otras formas de opresión como la clasista o la racial según Scott. Finalmente hay que reflexionar en cómo romper con las diferencias sociales que se establecen a partir del sexo al que se pertenece, en otras palabras, terminar con el mito de que existen características innatas masculinas y femeninas. Lo masculino se vincula con la fuerza, la inteligencia, el trabajo, mientras que lo femenino se asocia con la reproducción y por tanto con el hogar, los cuidados; pero, mientras que lo primero es producto de un desarrollo en los hombres, lo segundo es natural y por tanto, menos importante.

Otro elemento que ayuda a comprender lo anterior es rescatar lo que la misma Scott plantea sobre los sistemas simbólicos

[...] las formas en que las sociedades representan el género, hacen uso de éste para enunciar las normas de las relaciones sociales o para construir el significado de la experiencia. Sin significado, no hay experiencia; sin procesos de significación no hay significado (lo que no quiere decir que el lenguaje lo sea todo, sino que una teoría que no lo tiene en cuenta ignora los poderosos roles que los símbolos, metáforas y conceptos juegan en la definición de la personalidad y de la historia humana). ${ }^{7}$

Sin sobrevalorar la importancia del lenguaje, es fundamental rescatar los procesos de significación que se construyen a partir de ser hombre o ser mujer. Ubicándonos en el escenario de una guerra, el discurso, la simbolización y todos aquellos elementos que van formando la perso-

\footnotetext{
6 Pierre Bourdieu, "La dominación masculina", La Ventana, núm. 5, Guadalajara, Universidad de Guadalajara, julio, 1996, p. 28.

${ }^{7}$ Scott, op. cit., p. 282.
} 
nalidad de los combatientes, de los agredidos, de víctimas y victimarios, son esenciales para rescatar la subjetividad de quienes, como algunas mujeres, se incorporan a un espacio violento, desafiando muchos símbolos patriarcales. Ellas fueron definiendo una nueva identidad que se fue redefiniendo para dar cuerpo a formas de autorrepresentación que no van en línea recta.

Un planteamiento que cuestiona algunas limitantes del feminismo urbano y que se adentra en un contexto latinoamericano, lo hace Mercedes Olivera al afirmar:

Nuestras posiciones pueden enriquecerse si para hacer juicios nos detenemos a ver la realidad de la existencia de las mujeres, la que viven y no sólo la que debieran vivir de acuerdo a nuestra posición feminista. Debemos ubicarnos en el contexto político real. Cada vez más autoritario y corrupto en que actúan. Nuestro discurso se enriquecería si desarrolláramos la capacidad de aceptar la heterogeneidad del desarrollo social, la diversidad de ritmos de cambio y la variedad de culturas existentes en el país [...]. ${ }^{8}$

Por su parte Aída Hernández, en relación con la cuestión indígena, habla del replanteamiento teórico del concepto de género, pensándolo como una categoría multidimensional. Además del reconocimiento que da al tomar en cuenta la etnia y a la clase para entender los procesos identitarios del México multicultural, pero ello, afirma, se ha logrado gracias a los aportes de las mujeres indígenas. ${ }^{9}$

Olivera, partiendo de la realidad de las indígenas campesinas del estado de Chiapas, señala que su identidad como campesinas es más fuerte que su identidad de género, pero que además de la limitante que puede ser militar en organizaciones donde los dirigentes siempre son hombres, ellas se han atrevido a hablar y que a partir de allí se puede

8 Mercedes Olivera, "Práctica feminista en el movimiento zapatista", Lolapress. Revista Feminista Internacional, núm. 5, Berlín-Montevideo, mayo-octubre, 1996, pp. 29-31.

9 Rosalva Aída Hernández Castillo, "Entre el etnocentrismo feminista y el esencialismo étnico. Las mujeres indígenas y sus demandas de género", Debate feminista, vol. 24, año 12, México, octubre, 2001, pp. 206-229. 
plantear un avance, a pesar de que todavía predominan las demandas económicas a las políticas. ${ }^{10} \mathrm{La}$ idea de Hernández sobre la doble militancia reviste gran importancia, sobre todo en lo que a la riqueza para el feminismo implica.

A diferencia del movimiento feminista nacional, las mujeres indígenas han mantenido una doble militancia, vinculando sus luchas específicas de género a las luchas por la autonomía de sus pueblos, de ahí su interés por continuar integradas al Congreso Nacional Indígena. Esta doble militancia, sin embargo ha tenido que enfrentar muchas resistencias, tanto por parte del movimiento feminista como por parte del movimiento indígena. Consideramos que ambos movimientos se han visto beneficiados de esta doble militancia: las feministas al verse obligadas a incorporar la diversidad cultural a sus análisis de la desigualdad de género y el movimiento indígena al tener que incorporar el género a sus perspectivas sobre la desigualdad étnica y clasista que viven los pueblos indios. ${ }^{11}$

Éste es un elemento central para que tanto el movimiento feminista - fundamentalmente urbano y de clase media - recapacite sobre la diversidad cultural de las mujeres como el propio movimiento indígena, básicamente integrado por un campesinado pobre, recupere reivindicaciones específicas de sus mujeres. En otras palabras, la identidad de ser mujer no es la única ni es determinante, no deben dejarse de lado otros aspectos igual de importantes.

Comparto entonces la idea del feminismo como una corriente teórica que desea romper con todo tipo de opresión, que comenzó por cuestionar la desigualdad de los sexos, pero rompió este marco para desafiar a una sociedad que está plagada de diferencias y exclusiones. Ahora bien, esta corriente del feminismo también debe enriquecerse con las perspectivas que dan la diversidad de las miradas y las voces femeninas.

10 Olivera, op. cit.

11 Hernández, op. cit. 


\section{DE LA REPRESIÓN A LAS FORMAS DE RESISTENCIA}

Y A LA RESIGNIFICACIÓN DE LA IDENTIDAD

La búsqueda de una sociedad más justa en Guatemala pareciera una constante en su larga historia reciente y la represión aparece recurrentemente como respuesta a esa búsqueda. El poder en el país estuvo en manos de los militares en el transcurso de numerosos años del siglo XX, algunos se presentaron con la fachada característica de los dictadores populares durante la primera mitad de la centuria, como el general Jorge Ubico y otros que con el poder del ejército se valieron de su cargo para, con el pretexto de luchar contra la guerrilla y la invasión comunista, masacrar a comunidades enteras y volverse los nuevos propietarios de las tierras que quedaban abandonadas o que eran arrebatadas con lujo de violencia. Así además del poder político se apropiaron del poder económico. La exclusión política es una de las características del sistema guatemalteco durante casi todo el siglo pasado.

Por varios años coexistieron en Guatemala diferentes tipos de organizaciones populares que combinaron formas de lucha legal con grupos armados. Noticias sobre los primeros brotes militares insurgentes se remontan a la década de los sesenta. El movimiento popular que actuaba abiertamente en las ciudades - principalmente en el magisterio y grupos estudiantiles demandando democracia y respeto a la vida - transitaría un camino tortuoso para conseguir sus demandas ante las cuales sólo obtendría una mayor represión. Así como la lucha insurgente se valdría de organizaciones clandestinas y legales, la estrategia contrainsurgente combinaría la represión selectiva con la represión masiva empleando al ejército y a los paramilitares.

Las organizaciones guerrilleras en Guatemala aparecieron en la década de los años sesenta a raíz de la caída del presidente electo Jacobo Arbenz, ${ }^{12}$ organizada por la CIA. Con una clara influencia del triunfo de

12 Un trabajo documentado sobre este episodio histórico puede consultarse en Stephen Schlesinger y Stephen Kinzer, Fruta amarga. La CIA en Guatemala, México, Siglo XXI, 1982. 
la Revolución cubana, la formación de las Fuerzas Armadas Rebeldes (FAR) en 1962 originó una larga historia de grupos rebeldes armados, éstos operaron en zonas de población no indígena desenvolviéndose en el Oriente y la capital del país. ${ }^{13}$ Sólo cuatro años tuvieron de vida las primeras FAR pues en 1966 se desmembró la organización debido a la participación del ejército, la utilización sistemática del terror y la asesoría de Estados Unidos. Sin embargo, a pesar de todo ello, el gobierno no consiguió cortar de tajo el recurso de la lucha armada como una posibilidad de cambio. Se reestructurarían posteriormente a la par del nacimiento de nuevos grupos armados.

Inmediatamente después de las Jornadas de marzo y abril de 1962, se inicia la organización de la lucha armada con las primeras Fuerzas Armadas Rebeldes (FAR). En ellas participamos varias mujeres que iniciábamos también nuestra lucha de liberación femenina. En ese entonces no lo sabíamos, pero en una sociedad tan machista como la guatemalteca, fuimos verdaderas pioneras. ${ }^{14}$

Hay que reflexionar la frase "en ese entonces no lo sabíamos" para comprobar la importancia del rescate de experiencias de mujeres en el marco de una guerra. Varias de ellas participaron en la organización de la lucha armada - en una estructura predominantemente masculinadesde la temprana década de los sesenta, en un pequeño país que comenzaba a convulsionarse.

Los acontecimientos posteriores incrementarían el recurso de las armas pues los escasos cauces políticos se iban cerrando uno tras otro. Castillo Armas, el militar golpista fue asesinado. Llegó al poder otro militar: el coronel Miguel Ydígoras. Jóvenes militares simpatizantes de Arbenz intentaron un golpe de Estado que fracasó. Con el frustrado alzamiento militar algunos de los oficiales golpistas también encontraron

13 Ricardo Falla, Masacres de la selva. Ixcán, Guatemala (1975-1982), Guatemala, Editorial Universitaria, 1992.

14 Testimonio de Aura Marina citado en Norma Stoltz Chincilla, Nuestras utopías. Mujeres guatemaltecas del siglo XX, Guatemala, Magna Terra Editores, 1997, p. 102. 
todos los caminos cerrados y buscaron en la guerrilla la posibilidad de tomar el poder. El recurso de las armas se perfilaba no sólo como el adecuado, sino como el único. ${ }^{15}$

Yo creo a la distancia, valorando lo que hicimos, que valió la pena hacerlo, por supuesto que ahorita justamente está en duda la validez de tantas cosas, que si valió la pena la guerra o no. Yo creo que lo bueno y lo malo que ha ocurrido y lo poco que se ha avanzado en el cumplimiento de los acuerdos de paz, en esta etapa, no hubiera sido posible de otra manera y que a nuestra generación realmente no le tocó otra alternativa. Yo, de hecho, nací con la contrarrevolución, había habido una, la revolución de octubre y todo el periodo democrático. Yo nací ya dentro de la contrarrevolución y durante muchos años no hubo más que gobiernos represivos, militares. No había opción, los partidos políticos en aquel entonces no eran ninguna opción para cambiar la situación, no había el status de participación política, yo creo que no hubo otra opción y que si ahorita estamos hablando de construir un estado de derecho, de construir la democracia, de relacionarnos de otra manera entre la sociedad, de construir una relación de no discriminación a los indígenas, todo eso es fruto de la guerra y de los acuerdos de paz o sea, aunque no nos guste la situación actual porque la verdad estamos enfrentando una situación muy difícil, un retroceso porque ya no solamente es que se interrumpió el cumplimiento de los acuerdos de paz,

${ }^{15}$ No coincido con una de las conclusiones de la Comisión del Esclarecimiento Histórico que dice: "Durante su investigación la $\mathrm{CEH}$ comprobó que el trabajo político de las organizaciones guerrilleras dentro de los diversos sectores de la sociedad fue orientado crecientemente a fortalecer su capacidad militar, en perjuicio del estilo de acción política propio de sectores democráticos. Asimismo, los intentos de otras fuerzas políticas para aprovechar los limitados espacios de participación legal fueron descalificados con radicalidad por algunos sectores de la insurgencia como 'reformistas' o 'disidentes', mientras las personas que pretendían mantenerse al margen del enfrentamiento eran tratadas con profunda desconfianza y hasta como potenciales enemigos, contribuyendo también por este lado a la intolerancia política y la polarización." Guatemala, Memoria del silencio. Tz'inil na 'tab'al. Conclusiones y recomendaciones del informe de la Comisión para el Esclarecimiento Histórico. Academia de Lenguas Mayas de Guatemala. s/a. En Guatemala se cerraron los cauces políticos, lo cual parece reconocer la Comisión al señalar los "limitados espacios" que, sin querer justificar sino comprender el proceso, pienso que eran prácticamente inexistentes para la participación legal. El camino de la guerra no era una opción, fue de alguna manera una imposición de la intolerancia. 
en algunas cosas se avanza muy lentamente pero en otras, hay retrocesos, ahí a pesar de todo, creo que sí valió la pena. ${ }^{16}$

Es importante retomar las palabras dichas por esta mujer ex militante de una organización político-militar porque no muestran desesperanza ni negación total de lo vivido. Prevalecía la idea de que no había opción, en Guatemala la vía legal y el camino electoral estaban cerrados y no era el discurso quien lo pregonaba, fueron los hechos que cotidianamente lo confirmaban. Ahora puede concluirse fácilmente que los costos no se equiparan a los logros, pero en las décadas de los setenta y ochenta, la perspectiva era otra, no sólo en el ámbito nacional sino también en el internacional. Es necesario añadir que la lucha por abrir espacios se dio desde varios frentes, no sólo el militar.

Entre el movimiento popular que actuaba en los marcos legales y el movimiento guerrillero se podría hablar de la coincidencia en dos reivindicaciones: el derecho a la vida y el derecho a una vida digna, entendiendo por la primera, el alto tanto a la represión como a la tortura y a los asesinatos y por la segunda, tener acceso a la salud, a la educación, a un trabajo bien remunerado, en síntesis, el fin a la explotación, a la miseria. Ello nos presenta un doble panorama: bajo nivel de vida y violencia y terror ejercidos desde el poder para contener las muestras de descontento. El terremoto de 1976 fue un elemento adicional que incrementó las tensiones y que de alguna manera se constituyó en el resurgimiento del movimiento sindical; también se convirtió en un pretexto para que soldados norteamericanos que hablaban de reconstrucción ejercieran vigilancia entre los sindicalistas más activos y dejaran constancia nuevamente de que la intervención extranjera sería permanente. Varias manifestaciones fueron realizadas en la ciudad de Guatemala exigiendo mejores condiciones de trabajo y el alto a la represión,

16 Entrevista realizada a Laura, ex militante del EGP (Ejército Guerrillero de los Pobres), en la ciudad de Guatemala el 26 de julio de 2002. Todas las entrevistas que se citan fueron realizadas por mí, SS. 
en ellas sobresalía la presencia campesina que además era la víctima más directa de las violentas políticas estatales. ${ }^{17}$

Sería en 1972 cuando surgieron dos nuevas organizaciones guerrilleras: la Organización Revolucionaria del Pueblo en Armas (ORPA) con influencia en el altiplano y la bocacosta y el Ejército Guerrillero de los Pobres (EGP) que actuaría en el Ixcán. Guatemala en el marco de Centroamérica no es un caso aislado de grupos guerrilleros y la década de los setenta sería especialmente fructífera para este tipo de organización, los sandinistas en Nicaragua triunfarían en 1979 y en El Salvador también cobró fuerza el Frente aglutinando organizaciones armadas que compartían las mismas aspiraciones.

La religión y las diferentes iglesias serán un elemento que se deberá tomar en cuenta en toda la historia guatemalteca del siglo XX a la par de organizaciones sindicales, partidistas o guerrilleras. Tanto la Iglesia católica como diferentes variantes del protestantismo buscaron diversos caminos para organizar a los pueblos indígenas. Particularmente, la Iglesia católica fue blanco de ataque en el largo proceso de represión; a raíz de la persecución hacia religiosos y religiosas nacería la Iglesia Guatemalteca en el Exilio (IGE). Como ha ocurrido en la historia de la Iglesia católica, sus intereses pueden colocarla en uno u otro bando y pueden también dividirla. ${ }^{18}$ Cuando se trató de boicotear al gobierno electo de Jacobo Arbenz, fue también la Iglesia la que organizó la Acción Católica para hacer frente a las políticas que atentaban contra la concentración de la tierra. Influir en los pobres, en los indígenas, en mujeres y hombres para presionarlos con el miedo del comunismo fue el objetivo

17 Véase Ivon Le Bot, La guerra en tierras mayas. Comunidad, violencia y modernización en Guatemala (1970-1992), México, FCE, 1995 (Sección de obras de sociología).

18 Un trabajo sobre la Iglesia católica guatemalteca durante la guerra que nos ubica en esta perspectiva conflictiva entre el compromiso con el oprimido o con el poder que reprimía, es el de Luis Samandú, Hans Siebers y Óscar Sierra, Retos de la Iglesia católica en una sociedad en crisis, San José, Costa Rica, Departamento Ecuménico de Investigaciones/Consejo Superior Universitario Centroamericano, 1990 (Col. Sociología de la religión). 
principal de este movimiento que impulsaba "la voluntad divina" como razón de la desigualdad social.

Sin duda, un cambio fundamental se dio en la década siguiente cuando los catequistas comenzaron a hablar del "reino de Dios en la Tierra" ${ }^{19}$ Esto significó un parteaguas en la idea que se tenía de la voluntad divina de esperar al reino de dios en el cielo. La colonización de las selvas del Petén y del Ixcán avanzó simultáneamente a este proceso; la Iglesia promovió la organización de cooperativas en los pueblos en formación; un elemento positivo que hay que resaltar fue la integración de diferentes etnias. También en esta década hicieron sus primeras apariciones los temibles escuadrones de la muerte.

Varios testimonios recogen la experiencia de lo que significaba el EGP. Formado en sus orígenes sólo por hombres, varias mujeres se integrarían posteriormente a sus filas. Al organizarse clandestinamente, comenzaron por ganar la simpatía de algunas comunidades indígenas con el fin de fortalecerse. En las memorias de Payeras ${ }^{20}$ se recrean algunos de los primeros momentos y obstáculos que hubo de sortear el grupo que intentaba ser la vanguardia armada del pueblo guatemalteco. Los jóvenes guerrilleros comenzaron por buscar a los hombres de las comunidades para incrementar el número de sus integrantes.

Esa noche reunimos a los varones del poblado, les explicamos extensamente la razón de nuestra lucha y anunciamos solemnemente que íbamos a vencer. ${ }^{21}$

Estos originales quince hombres que formaban el EGP fueron buscados desde que ingresaron a México tanto por el ejército guatemalteco como por su homólogo mexicano, sólo que en ese momento no pudieron encontrarlos. $^{22}$ Varias mujeres se unieron a la guerrilla más adelante, las primeras vendrían de las ciudades.

19 Véase Elizabeth Burgos, Me llamo Rigoberta Menchú y así me nació la conciencia, 8a. ed., México, Siglo XXI, 1992 (Historia inmediata).

${ }^{20}$ Mario Payeras, Los días de la selva, 8a. ed. en español, México, Joan Boldó i Climent Editores, 1989.

${ }^{21}$ Ibid., p. 30.

22 Véase Falla, op. cit., y Le Bot, op. cit. 
El ejército rebelde estuvo integrado por hombres y mujeres, muchos de los combatientes eran indígenas y se enfrentaban a un ejército con composición eminentemente masculina. Las mujeres indígenas fueron engrosando las filas guerrilleras; cuando algún prisionero del sexo femenino era capturado, se buscaba humillarle más, precisamente por ser mujer, india y pobre, a pesar de que muchos de los integrantes del ejército federal también sean pobres e indios, pero no mujeres. Que una mujer ocupara un lugar reservado para hombres, que reuniera tres características indeseables en el grupo enemigo, era motivo mayor para hacérselo sentir. No estoy diciendo que a los hombres prisioneros no se les humillara, lo que estoy señalando es que las mujeres recibirían un trato diferente, con el que se les advertía, se les mostraba que estaban transgrediendo un espacio no asignado, que no podían equipararse al enemigo armado, que la disciplina castrense es masculina. Por supuesto la violencia sexual era inevitable.

Quince días estuve allí en manos del ejército. Después de estar como cinco días amarrada y sin ver a nadie, entonces en la noche pues, me sacaban afuera en el sereno y me amarraron; y de las cuatro a las nueve de la mañana que me tiran y me metieron tierra, a las siete me llevaron a un túnel donde me metían algodón y cuando miraban que ya me estaba ahogando... me lo sacaban... a las nueve empezaron a quemarme, todavía tengo señales en la espalda donde me quemaban. Los labios, aquí, no los tenía yo así, me quemaron los labios, la nariz, me cortaban con gillette. No sé, supongo, porque lo que hacían era bajarme o si no, me amarraban una agujeta en el pescuezo y lo jalaban sobre el techo. En una ocasión me hicieron, porque me mostraban muchas fotos de gente, de mi familia, de otras personas, andamos, a dónde está el campamento guerrillero decían, o sea ¿dónde? Camina y dónde están tus compañeros decían, pero yo no sé, dios mío que me ayude. ${ }^{23}$

Una mujer sola, que fue capturada y que se encuentra en "manos del ejército", esto es, en manos de hombres que la hacen prisionera por-

${ }^{23}$ Entrevista realizada a una ex militante del EGP en la ciudad de Guatemala, el 25 de julio de 2002. 
que es enemiga, a quien torturan para obtener información. Una indígena que no quiso hablar pero que quedó con profundas marcas después de su cautiverio, no sólo las visibles sino las que después la empujaron a incorporarse más profundamente en la lucha por diferentes vías pues dijo en otro momento, cuando se había curado de sus heridas "sólo me metieron más coraje".

La década de los ochenta marca el ascenso en una política represiva sin parangón. La aplicación sistemática de la estrategia de tierra arrasada condujo a formas de resistencia de la población agredida en busca de la sobrevivencia. Así nacieron las Comunidades de Población en Resistencia (CPR) y la población refugiada que cruzó la frontera escapando de una muerte segura.

Nosotros formamos la población en resistencia, ya no podíamos salir porque había destacamentos como a unas dos horas de donde nosotros podíamos salir para la ciudad, y para la parte de abajo que conducía a la frontera había otro destacamento, entonces había control. Había control arriba y había control abajo y ya no había forma de salir, entonces nosotros lo que hicimos fue agarrar hacia las parcelas donde más o menos sabíamos que había alguna cosa de comer y entonces, nosotros salimos desnudos, descalzos con ropas menores de dormir, sin nada, sin ropa, sin llevar nada, nada, nada, todo se quemó, y entonces ya nos vimos ahí sí que en ropas menores. Y nos llevamos a los niños, logramos salvarlos a algunos, y pues empezamos a juntarnos así de forma muy dispersamente, porque la gente salió de muy diferentes maneras. ${ }^{24}$

Esta nueva forma de vida impulsó a muchas mujeres a actuar como no lo habían hecho antes. La seguridad era responsabilidad de todos, de mujeres y hombres, vivir a la intemperie, cargando miedo y desesperación pero buscando conservar la vida, creó no sólo una identidad colectiva de pertenencia a un grupo específico, sino la certeza de que la actividad de cada uno era determinante para mantenerse vivos. El cui-

24 Entrevista realizada a María Teresa, militante de varias instancias organizativas y con una experiencia participativa muy amplia, en la ciudad de México el 24 de abril de 2001 . 
dado de niños y enfermos se colectivizó así como la preparación de alimentos; rompieron, obligados por las circunstancias, los papeles asignados. Sobrevivir a una masacre siendo testigos de muertes violentas, los rescató con una perspectiva de quien vuelve a nacer.

Otra forma de resistencia fue el refugio. En ella muchas mujeres conocieron estructuras organizativas que darían otro sentido a sus vidas.

Nació Madre Tierra y así de que más o menos la organización seguía y se estuvo luchando, se capacitó para poder regresar al país otra vez, ¿que íbamos a hacer cuando íbamos a estar aquí? ¿Nos íbamos a quedar igual o íbamos a echar a andar lo que aprendimos mientras estuvimos afuera? Entonces quizás el objetivo muchas lo traíamos, lo que pasó es que no todas las que nos venimos de Campeche estaban organizadas, así más o menos ellas quisieron regresar, por querer regresar, pero al venir aquí ya más o menos miraron como empezamos a trabajar y así fue como ya se volvió otra vez a conjuntar las ideas y todo eso de cómo íbamos a trabajar... No sabía, hasta ahorita que más o menos el trabajo me enseñó como iba a ser yo más lejos, pero yo escuela no tuve, entonces no tuve la oportunidad, pues cuando era yo chiquita. Pero sí mis ideas y todo eso, mi ser, mi modo me hizo que la gente me conociera y todo eso, entonces lo he sacado muy, muy bonito los trabajos adelante, adelante y por eso es que todavía estamos viendo del lado de la organización de Madre Tierra, más o menos ahorita, ya se agarró mucho. ${ }^{25}$

Salieron huyendo, también con las manos vacías buscando conservar la vida al cruzar la frontera. Ya en otro país y en su calidad de refugiados, muchas mujeres comenzaron a incorporarse a grupos que darían forma a una organización. En ésta ellas pudieron expresar su inquietud por el retorno y pidieron capacitarse para cuando volvieran. Lo que aprendieron lejos podía dejarse allí o reestructurarse al regreso, por eso la frase "¿nos íbamos a quedar igual o íbamos a echar a andar lo que aprendimos mientras estuvimos afuera?" es del todo significativa. No volvieron las que se fueron, fue el trabajo organizativo la que les enseñó

${ }^{25}$ Entrevista realizada a Ramona, ex refugiada y militante de la organización de mujeres Madre Tierra, en La Lupita, Guatemala, el 30 de julio de 2002. 
cómo valorar su actividad y la importancia de continuarla encontrando un nuevo sentido a su vida. Escuela no tuvo pero fue descubriéndose como una mujer nueva dentro de una estructura organizativa.

Otras mujeres que no fueron víctimas directas de la violencia permanecieron en el país recorriendo un camino doloroso, viviendo la experiencia de ser familiar de quien ya no estaba "ni vivo ni muerto" sino como desaparecido.

Voy a contar un poco de nuestra historia, porque nosotros realmente somos una organización que nació en los tiempos de la violencia que estaba bastante fuerte y nos organizamos un grupo de mujeres, fue en medio de esa ola de terror que nos tocó vivir. Sin embargo realmente somos un grupo de mujeres las que nos atrevimos, en ese tiempo, a salir a las calles a gritar, un alto, a hacer un alto a la violación a los derechos humanos que en ese entonces, fue muy fuerte; sigue siendo, pero en ese tiempo creo yo que estaba peor. Entonces nos organizamos un grupo de mujeres, aquí, en la capital, pero luego hicimos llamado de aquí hacia el interior del país por medio de los medios de comunicación y vino mucha gente del interior. Eran mujeres indígenas que siendo el temor que tenían ellas allá, siendo que les costaba salir de su comunidad, ya que tenían que dar aviso a los militares que estaban ahí cuidando, digamos su comunidad, pero ellas tenían que ver de qué manera, qué estrategia tomaban para poder salir de allá y así llegaron acá a buscar el apoyo de este grupo de mujeres que está luchando por los desaparecidos. ${ }^{26}$

La pérdida de un ser querido daría fuerza a muchas mujeres para salir de su espacio (fuera el que fuera: la casa, el campo, un trabajo remunerado) e introducirse por un sendero de muerte e impotencia que las marcó profundamente. Para algunas, la militancia comenzaría precisamente en el momento en que pierden a uno de sus hijos, ya sea porque el sacrificio de éste les empujó a tratar de continuar lo que él ya no pudo, o porque al buscar a ese ser querido, se involucraron en actividades nuevas, difíciles y generalmente dolorosas. Las amenazas y el mie-

26 Entrevista realizada a María Emilia, fundadora del GAM (Grupo de Apoyo Mutuo), en la ciudad de Guatemala el 31 de julio de 2002. 
do no las doblegaron, la imagen de aquel hijo que ya no verían era más fuerte, sería precisamente esa vida perdida la que les empujó a actuar como antes no lo habían hecho.

Hablar de vivencias tan fuertes como las de una guerra significa transformar el dolor en palabras, pero también en esperanza. El contexto de la guerra revolucionaria en Guatemala estaba imbuido del deber ser. Bajo el discurso del socialismo, del hombre nuevo, de la lucha por la patria, y una larga cadena de compromisos sobre lo que significaba la experiencia de la revolución, tanto para combatientes como para bases de apoyo, los sentimientos quedaban fuera. Pero hablar de guerra y mujeres me invitó a rescatar lo que se entiende por la subjetividad en un contexto del feminismo: "Uno de los núcleos centrales en la investigación feminista es el que se refiere a la constitución de la subjetividad, o dicho con otras palabras, la diferencia sexual como experiencia fundante del sujeto que produce una constitución desigual tanto psíquica como socialmente". 27

Tomando como fundamento el hecho de un sujeto desigual y por tanto la necesidad de rescatar cómo este sujeto (hombre o mujer) vive diferente la guerra. A través del análisis de sus voces se desentrañan las experiencias que construyeron sujetos, son sus vivencias vueltas palabras las que darán sentido a su propia interpretación. Estoy valorando sujetos sociales mediante múltiples simbolizaciones que se significan en frases, cómo es que estas mujeres atribuyen un sentido a sus vivencias bajo determinado entorno que va construyendo cierta identidad. La mujer sobreviviente, la que logró cruzar dos veces la frontera, la madre del desaparecido, la viuda monolingüe que no tiene ni siquiera la certeza de serlo, sólo dejó de ver a su esposo porque se lo llevó el ejército pero no sabe de sus restos.

Hablando de lo limitante que puede ser la "objetivización de los actores", Lerner dice que esta perspectiva incorpora una serie de dimensiones para analizar los comportamientos de los individuos que pue-

${ }^{27}$ Millán, op. cit., p. 25. 
den ser biológicas, económicas, políticas, etc., pero que omite las cuestiones subjetivas, simbólicas y valorativas:

De ahí la necesidad e importancia de combinar diferentes formas de acercamiento o bien de privilegiar los enfoques correspondientes a la investigación cualitativa. Estos últimos, cuya preocupación central es conocer e interpretar la "subjetividad de los sujetos", buscan comprender el punto de vista de los actores de acuerdo con el sistema de representaciones simbólicas y significados en su contexto particular. Por ello, estos acercamientos privilegian el conocimiento y comprensión del sentido que los individuos atribuyen a sus propias vivencias, prácticas y acciones. El supuesto fundamental consiste en considerar que los comportamientos humanos son resultado de una estructura de relaciones y significaciones que operan en la realidad, en un determinado contexto social, cultural e ideológico; realidad que es estructurada o construida por los individuos, pero que a su vez actúa estructurando su conducta. ${ }^{28}$

Al rescatar el punto de vista de los actores, en este caso de las mujeres, estoy interpretando hechos sucedidos desde su experiencia en un determinado contexto social, misma que han vivido, que les ha marcado, que ha dado un nuevo significado a esa vida, ubicada en un escenario bélico. Recrear una perspectiva en la cual se enfatiza al sujeto social y en la cual no se puede dejar de lado las desigualdades sexuales que se vuelven sociales. Sin obviar otras diferencias como las de clase, etnia y etaria. Son representaciones simbólicas las que estas mujeres han ido construyendo.

Quiero asimismo plantear una reflexión de lo que pudo haber sido el racismo hacia las mujeres en un escenario de guerra. Pensemos en esas mujeres viudas, campesinas e indígenas del país centroamericano interrogando a miembros del ejército o de la policía, por el paradero de sus esposos. Ellas se enfrentaron a hombres con un poder, no es extraño que

28 Susana Lerner, "La formación en metodología cualitativa. Perspectiva del programa de salud reproductiva y social", en Ivonne Szasi y Susana Lerner [comps.], Para comprender la subjetividad. Investigación cualitativa en salud reproductiva y sexualidad, México, Colmex, 1999, p. 13. 
ellas fueran monolingües, que además estuvieran cargando con la incertidumbre del paradero de algún familiar. Pero conocer el destino de éste fue más fuerte que su miedo y que su impotencia. Fueron a buscarlo y el trato que recibieron es el que se le da a una mujer, pobre y considerada de una etnia inferior, pero, en un momento de guerra también es vista como parte del enemigo; si era una lucha de pobres contra ricos, ellas eran susceptibles de ser parte del bando contrario. Así entonces, se les humillará por estas cuatro razones y se les tratará como seres inferiores por quienes detentan el poder, que son hombres y armados. La demanda por averiguar el paradero de los desaparecidos se convirtió en una forma de cuestionar al poder despótico que se valía del escarnio como respuesta:

En relación con los desaparecidos, nosotros hacíamos recursos de exhibición personal, los presentábamos. Varias veces los presentamos en el Ministerio Público, lamentablemente esos recursos quedaron ahí, en las oficinas, no les daban ningún trámite, y luego pues era muy difícil. Nosotros llegamos a varios lugares donde nos decían que ahí había varias personas que habían ido a enterrar, íbamos a ver y lamentablemente pues esto no, no, nunca progresó. Todavía, como quien dice, tuvimos el atrevimiento de ir a preguntar a los destacamentos militares y ahí pues, con muchos riesgos pero sí se hizo, y tampoco nos daban información... Cuando nosotros íbamos a la policía para reclamar a nuestros familiares, bueno, eso era así, esa gente nos trataba como, digamos, así muy sarcásticamente. Ellos eran abusivos hasta cierto punto y le contestaban a uno de una manera cruel, porque decían no, que si ellos [nuestros familiares] se fueron a los Estados Unidos, allá están, o que ellos se fueron porque no aguantaban a la mujer y entonces prefirieron irse, o que ellos se fueron a Nicaragua, o ellos se fueron a Cuba; pues si hubiera sido así, qué bueno verdad, porque algo hubieran hecho por otro lado, pero lamentablemente eso no sucedió así, de ninguno de los desaparecidos. ${ }^{29}$

Mujeres buscando a sus hijos o a sus esposos en cualquier parte que los cauces legales les permitían, iban al Ministerio Público, acudían a

29 Entrevista realizada a María Emilia, fundador del GAM, en ciudad de Guatemala el 31 de julio de 2002 . 
quienes encubrían la desaparición "tuvimos el atrevimiento de ir". Buscaron, buscaron y buscaron, pero en su gran mayoría, no los encontraron y cabe decir, no los encontrarán. Muchas de estas mujeres se organizarían más adelante o bien en la Coordinadora Nacional de Viudas de Guatemala (CONAVIGUA) o en el Grupo de Apoyo Mutuo (GAM) con la esperanza de que estando unidas podrían saber de sus familiares o ser menos vulnerables. La respuesta de las autoridades era recurrente: pedían pruebas de la desaparición, y como dice una de las fundadoras del GAM, "la única, la única prueba que teníamos era que nuestro familiar ya no estaba".

Por último unas palabras en torno a cambiar la percepción que las mujeres tienen sobre sí mismas, cuando comienzan a autorrepresentarse como seres participativos.

Yo comencé a trabajar en una organización de la Iglesia, que hay de muchas, ahí más que todo, nosotros formamos grupos de mujeres como más amplios que los hombres; ellos eran de comités de una iglesia y las mujeres casi no, las mujeres siempre decían que no podemos, que no sabemos nada, pero entonces cuando yo crecía pues a mí me gustaba participar. Y por medio de que bueno, aunque mi papá es pobre y todo también, pero apenas me pudieron regalarme dos años en la escuela, entonces ya con esos dos años de la escuela, ya entendía algunas palabras, caligrafía y a escribir algunas letras ya, entonces ya con eso pues me gustaba participar, entonces estaba en la iglesia, pues nos animamos con las mujeres y que también nosotros podemos también participar dentro de un servicio religioso, y que lo celebran los hombres sábado o domingo, también cantan, pues rezan y entonces nosotros también podemos rezar y podemos cantar y entonces y así nos fuimos animando nosotras las mujeres. ${ }^{30}$

\section{REFLEXIÓN FINAL}

En las líneas precedentes he dado espacio a voces femeninas en un contexto bélico. Voces que traducen identidades surgidas a partir del conflic-

30 Entrevista realizada a Candelaria, integrante de CONAVIGUA en la ciudad de Guatemala el 26 de julio de 2002 . 
to y la violencia pero que no subrayan a la víctima sino a quien continúa con vida luchando por encontrarle significado. En medio de la guerra, la mayoría de las vivencias se relacionan con la muerte, se le vive muy de cerca, con lo que la vida conservada surge con nuevas identidades.

Para gran parte de la población guatemalteca, las más de tres décadas de guerra son tiempo suficiente para cargar con cicatrices difíciles de borrar. La guerra significaba el uso de la violencia a la que se le puso el apellido de revolucionaria pero que hizo frente no sólo a una violencia institucional, sino que abarcó espacios más amplios en los cuales la guerra contrarrevolucionaria se convirtió en una razón para conservar el poder, sin importar los costos. Hombres y mujeres fueron blancos de la violencia pero esta diferencia construida socialmente da forma a identidades diversas.

La represión selectiva en Guatemala hacia los hombres, creó un nuevo sector dentro de la población: las mujeres viudas. Ellas valoraron que lo primero que deseaban era conocer el paradero de sus esposos que al paso de los días no volvían, como lo habían prometido quienes se los llevaron, así, incrementando su número, su desconsuelo y la necesidad de conseguir información, decidieron unirse y lo hicieron. Las viudas no eran unas cuantas, eran muchas y compartían una identidad que las hacía fuertes: eran mujeres, eran pobres, eran viudas, la mayoría monolingüe y se enfrentaban a un poder militar y racista que las subestimaba primero por ser mujeres, pero después por ser pobres e indígenas, que las humillaba. Ante lo cual ellas se unieron para fortalecerse.

La violencia propia de la guerra fue reproduciendo un ambiente de impotencia, particularmente en las mujeres, asimismo fue desarrollando en sus mentes la idea de la importancia de estar organizadas. Muchas identidades se cruzaron: ser mujeres, ser pobres, ser monolingües, ser indígenas, ser desplazadas, ser refugiadas, ser viudas. Y todas ellas - de una u otra manera - se convirtieron en motor de lucha, en razón de continuar viviendo, en aras de organizarse. Muchas mujeres han dado ejemplo de entereza y valentía, de rescatar de entre lo perdido las fuerzas para continuar, para hacer frente a esa violencia y denunciarla com- 
batiéndola. Estas mujeres no quisieron quedarse como víctimas pasivas, se convirtieron en sobrevivientes activos. Esta experiencia debemos considerarla una muestra de la capacidad de resistencia de hombres y mujeres violentados. Si las formas de la violencia no pararon su variedad, las formas de la resistencia son ejemplo de cómo se puede actuar cuando se trata de conservar la vida. En la experiencia guatemalteca, grandes núcleos de población encontraron en las montañas o en suelo extranjero, el espacio para sobrevivir, y tanto hombres como mujeres, además de negarse a la muerte, se organizaron para vivir. Conocieron estructuras organizativas que sólo la esperanza puede enseñar.

La idea de estar organizadas fue formando una conciencia nueva en muchas mujeres que la fueron incorporando a su lucha diaria. Esto significa que fue un contexto desfavorable el que creó las condiciones para que mujeres que cargaban miedo, enfermedades y subordinaciones varias, lograran crear un nuevo ambiente en el que comenzaron a valorarse. La violencia del ejército las transportó a un mundo diferente en el que aprenderían de nuevas vivencias pero, sobre todo, rescatarían la importancia de la organización que para muchas mujeres fue coyuntural pero que para otras, es cierto, la minoría, se convirtió en una razón de vida.

\section{BiBLIOGRAFÍA}

Bourdieu, Pierre, "La dominación masculina", La Ventana, núm. 5,

Guadalajara, Universidad de Guadalajara, julio, 1996.

Burgos, ElizABeth, Me llamo Rigoberta Menchú y asi me nació la conciencia, 8a. ed., México, Siglo XXI, 1992 (Historia inmediata).

FAlLA, RICARDO, Masacres de la selva. Ixcán, Guatemala (1975-1982), Guatemala, Editorial Universitaria, 1992.

Figueroa IBARRA, CARLos [comp.], El recurso del miedo. Ensayo sobre el Estado y el terror en Guatemala, Costa Rica, Programa Centroamericano de Investigaciones/Secretaría General del CSUCA/Editorial Universitaria Centroamericana, 1988. 
Los que siempre estarán en ninguna parte. La desaparición forzada en Guatemala, México, Grupo de Apoyo Mutuo/Centro Internacional para Investigaciones en Derechos Humanos/Instituto de Ciencias Sociales y Humanidades UAP, 1999.

GEM, Repensar y politizar la maternidad. Un reto de fin de milenio, México, Grupo de Educación Popular con Mujeres, A. C., 1994. Mitos, realidades y propuestas sobre la maternidad, México, Grupo de Educación Popular con Mujeres, A. C., 1994.

Hernández CAstillo, Rosalva Aída, "Entre el etnocentrismo feminista y el esencialismo étnico. Las mujeres indígenas y sus demandas de género", Debate feminista, vol. 24, año 12, México, octubre, 2001, pp. 206- 229.

LAGARDE, MARCELA, Los cautiverios de las mujeres: madresposas, monjas, putas, presas y locas, México, UNAM, 1997 (Col. Posgrado).

Le Bot, Ivon, "Guatemala: luchas sociales ante un horizonte de guerra 1973-1982", Cuadernos políticos, núm. 38, México, octubre-diciembre, 1983, pp. 23-35.

, La guerra en tierras mayas. Comunidad, violencia y modernización en Guatemala (1970-1992), México, FCE, 1995 (Sección de obras de sociología).

LeRner, SusAna, "La formación en metodología cualitativa. Perspectiva del programa de salud reproductiva y social", en Ivonne Szasi y Susana Lerner [comps.], Para comprender la subjetividad. Investigación cualitativa en salud reproductiva y sexualidad, México, Colmex, 1999.

Millán, MÁrgara, "Las zapatistas del fin del milenio. Hacia políticas de autorrepresentación de las mujeres indígenas", Chiapas 3, México, IIE/Era, 1996, pp. 19-32.

Derivas de un cine en femenino, México, Porrúa/UNAM-PUEG, 1999.

Olivera, Mercedes, "Práctica feminista en el movimiento zapatista", Lolapress. Revista Feminista Internacional, núm. 5, Berlín-Montevideo, mayo-octubre, 1996, pp. 29-31. 
[coord.], Nuestra experiencia ante los retos del futuro. Sistematización del trabajo de las mujeres de Mamá Maquín durante el refugio en México y su retorno a Guatemala, México, Organización de Mujeres Guatemaltecas Refugiadas en México "Mamá Maquín", 1999.

Payeras, Mario, Los días de la selva, 8a. ed., México, Joan Boldó i Climent Editores, 1989.

SAMANDú, LuIs, Hans Siebers y Óscar Sierra, Retos de la Iglesia católica en una sociedad en crisis, Costa Rica, Departamento Ecuménico de Investigaciones/Consejo Superior Universitario Centroamericano, 1990 (Col. Sociología de la religión).

SCHLESINGER, STEPHEN y Stephen Kinzer, Fruta amarga. La CIA en Guatemala, México, Siglo XXI, 1982.

ScOTT, JOAN W., "El género: una categoría útil para el análisis histórico", en Marta Lamas [comp.], El género: la construcción cultural de la diferencia sexual, México, Miguel Ángel Porrúa/PuEg, 1996, pp. 265-302.

Stoltz Chincilla, Norma, Nuestras utopías. Mujeres guatemaltecas del siglo XX, Guatemala, Magna Terra, 1997.

TuBERT, SilviA, Mujeres sin sombra. Maternidad y tecnología, Madrid, Siglo XXI, 1991 (Desigualdades y diferencias).

VÁzQuez, Norma, Cristina Ibáñez y Clara Murguialday, Mujeres-montaña. Vivencias de guerrilleras y colaboradoras del FMLN, Madrid, Horas y horas, 1995 (Cuadernos inacabados, 22).

Informe Guatemala, Memoria del silencio. Tz'inil na'tab'al. Conclusiones y recomendaciones del informe de la Comisión para el Esclarecimiento Histórico, Academia de Lenguas Mayas de Guatemala, s/a. 